\title{
Markers of inflammation, thrombosis and endothelial activation correlate with carotid IMT regression in stable coronary disease after atorvastatin treatment
}

Running Title: Soluble markers/carotid-IMT relationship after atorvastatin treatment

Damiano Baldassarre, $\mathrm{PhD}^{\mathrm{a}, \mathrm{b}}$, Beatrice Porta, $\mathrm{MD}^{\mathrm{c}}$, Marina Camera, $\mathrm{PhD}^{\mathrm{a}, \mathrm{b}}$, Mauro Amato, $\mathrm{PhD}^{\mathrm{a}}$, Massimo Arquati, MDc, Bruno Brusoni, MD ${ }^{\mathrm{d}}$, Cesare Fiorentini, MD ${ }^{\mathrm{a}, \mathrm{e}}$, Piero Montorsi, MDa, Salvatore Romano, MD ${ }^{\mathrm{f}}$, Fabrizio Veglia, $\mathrm{PhD}^{\mathrm{a}}$, Elena Tremoli, $\mathrm{PhD}^{\mathrm{a}, \mathrm{b}}$, and Michele Cortellaro, $\mathrm{MD}^{\mathrm{c}}$ (on behalf of the MIAMI Study Group)

a Centro Cardiologico Monzino IRCCS (D.B., M.C., M.A., F.V., E.T), and Institute of Cardiology (P.M.) via Parea 4, 20138, Milan, Italy; b Department of Pharmacological Sciences (D.B., M.C., E.T.), Milan University, via Balzaretti 9, 20133, Milan, Italy; ${ }^{\text {C Chair of }}$ Internal Medicine, Department of Clinical Sciences, L. Sacco Hospital (B.P., M.A., M.C.), Milan University, via G.B. Grassi 74, 20157, Milan, Italy; d Division of Cardiology (B.B.), Fatebenefratelli Hospital, C.so di Porta Nuova 23, 20121, Milan, Italy; e Division of Cardiology (C.F.), San Paolo Hospital, via Di Rudinì 8, 20142, Milan University, Milan, Italy; ${ }^{f}$ Division of Cardiology (S.R.), Ospedale Maggiore IRCCS, via F. Sforza 28, 20122, Milan, Italy.

Word count: abstract 229; main text ???; 50 references; 3 figures; 5 tables

This work was partially supported by a grant from Pfizer-Italia, Rome, Italy. 
Corresponding author:

Michele Cortellaro, MD,

Department of Clinical Sciences, L. Sacco Hospital,

via G.B. Grassi 74, 20157, Milan, Italy.

Phone +3902 39042320. Fax+3902 39042356. E-mail michele.cortellaro@unimi.it.

Keywords: atorvastatin; coronary artery disease; intima-media thickness; soluble markers. 


\section{Abbreviations}

MIAMI, Markers of Inflammation and Atorvastatin effect in previous Myocardial Infarction

$\mathrm{CAD}=$ coronary artery disease

ACS $=$ acute coronary syndrome

$\mathrm{BP}=$ blood pressure

$\mathrm{BMI}=$ body mass index

$\mathrm{C}-\mathrm{IMT}=$ carotid intima media thickness

$\mathrm{CC}-\mathrm{IMT}_{\text {mean }}=$ Mean IMT of common carotids

Bif-IMT $\mathrm{Imean}_{\text {mean }} \mathrm{IMT}$ of bifurcations

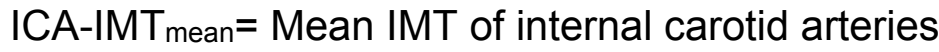

$\mathrm{IMT}_{\text {mean }}=$ Mean IMT of the whole carotid tree

$\mathrm{IMT}_{\max }=$ Max IMT of the whole carotid tree

hs-CRP = high sensitive C-reactive protein

TNF- $\alpha=$ tumour necrosis factor- $\alpha$

$\mathrm{IL}=$ interleukin

sCD40L = soluble CD40 ligand

MMP-9= matrix metalloproteinase- 9

TFPI-free= free tissue factor pathway inhibitor

TFPI-total= total tissue factor pathway inhibitor

sICAM-1= soluble intercellular adhesion molecule-1

sVCAM-1 = soluble vascular cell adhesion molecule-1

sE-selectin= soluble E-selectin

$\mathrm{vWF}=$ von Willebrand factor 


\section{Abstract}

Background and aims: MIAMI is a prospective multicenter clinical study designed to investigate the relationship between changes in carotid intima media thickness (C-IMT) and changes in circulating markers of inflammation, thrombosis and endothelial activation in stable coronary patients treated for $20 \pm 3.7$ months with $20 \mathrm{mg} /$ day atorvastatin.

Methods and results: 85 subjects had their C-IMT, blood lipids and soluble markers measured at baseline, at the $12^{\text {th }}$ month and at the end of the study. Almost all soluble markers decreased upon treatment except for high-sensitivity C-reactive protein (hs-CRP), interleukin-18 (IL-18), tissue factor pathway inhibitor-free (TFPI-free) and soluble vascular cell adhesion molecules-1 (sVCAM-1) which did not change significantly, and interleukin-6 (IL-6), tumor necrosis factor- $\alpha$ (TNF- $\alpha$ ) and soluble CD40 ligand (sCD40L) which increased. SCD40L, fibrinogen, tissue factor pathway inhibitor-total (TFPI-total), soluble intercellular adhesion molecules-1 (sICAM-1), sE-selectin, interleukin-8 (IL-8) and von Willebrand factor (VWF) changed significantly even after application of the Bonferroni correction for multiple comparisons. Changes in lipids did not correlate with C-IMT regression either when considered singly or when combined in a lipid score. Changes in soluble markers correlated poorly with C-IMT regression when analyzed singly, but strongly when combined in relevant composite scores (inflammation/coagulation score, endothelial activation score, soluble markers score and total score).

Conclusion: in patients with stable coronary artery disease treated with moderate doses of atorvastatin, carotid IMT regression correlated with changes of inflammation, thrombosis and endothelial activation profiles. 


\section{Introduction}

Large, randomized, controlled trials have documented that cholesterol-lowering therapy with 3-hydroxy-3-methylglutaryl coenzyme A reductase inhibitors (statins) reduces the risk of cardiovascular events across a wide range of plasma cholesterol levels in patients with or without a history of coronary artery disease (CAD).[1] Besides their inhibition of cholesterol synthesis, the beneficial effects of statins have been attributed in part to their suppression of the pro-inflammatory/pro-thrombotic pathways involved in atherothrombosis.[2]

The MIAMI study (Markers of Inflammation and Atorvastatin effect in previous Myocardial Infarction), is a prospective, open-label, multicenter study, designed to investigate the relationship between changes in carotid intima media thickness (C-IMT) and changes in circulating markers of inflammation, coagulation and endothelial activation in patients with stable CAD treated with a moderate dose of atorvastatin ( $20 \mathrm{mg} / \mathrm{day})$ for up to two years. The cross-sectional relationship between the soluble markers measured and the extent of carotid atherosclerosis at baseline has been previously reported.[3] We describe here the results of the longitudinal part of the study.

\section{Methods}

\section{Study population}

The design, methods and preliminary results of MIAMI study were as previously described.[3] Briefly, 85 patients with stable CAD (i.e., previous myocardial infarction more than two months before entry) were enrolled in 4 cardiology centers in Milan (Italy).

All patients were statin-naïve. Subjects already taking lipid-lowering medication required an 8-week washout period before enrolment. Ethical issues on this washout period were previously described.[3] The study complies with the Declaration of Helsinki 
and was approved by 5 independent ethics committees. All patients gave written informed consent.

Because all patients had a previous myocardial infarction and because clinical trials have demonstrated substantially improved outcomes with statins, it was deemed ethically unacceptable to randomize these patients to placebo. Accordingly, all patients were assigned to an active treatment with $20 \mathrm{mg} /$ day atorvastatin (kindly provided by Pfizer Italia).

Patients were maintained on their other medications including aspirin, $\beta$-blockers, diuretics and low-dosage ACE inhibitors, without change, throughout the study.

A baseline evaluation included demographic information, medication use, smoking and alcohol consumption, a physical examination with blood pressure, body mass index and fasting blood sampling. ECG was also recorded. Blood samples for central laboratory assay of lipid profile and plasma markers were collected at month 0,12 , and 24 , at the same time as C-IMT measurement. Patients not reaching the $24^{\text {th }}$ month follow-up underwent their last visit within the two weeks preceding the end of the study.

\section{Carotid IMT}

Carotid ultrasound was done by a single operator (M.A.) using an ACUSON Aspen system equipped with a 10-13 MHz linear array probe, and recorded on sVHS videotapes. The far wall of the left and right common carotid (CC), bifurcation (Bif) and internal carotid artery (ICA) were visualized in anterior, lateral and posterior projections.

The ultrasonic variables considered were the mean IMT of the common carotids (CC-IMT mean), bifurcations (Bif-IMT mean), internal carotid arteries (ICA-IMT mean) and the mean and maximum of the whole carotid tree (IMT mean and IMT $\max$ ). All these ultrasonic variables incorporate plaque(s). 
Ultrasonic measurements were performed by 2 readers (A.R. and E.O.) unaware of which trial they were evaluating, using specific software (M'Ath, Metris SRL France) that allows automatic edge detection of echogenic lines of the intima-media complex.

Progression of the C-IMT was estimated by assuming a linear trend with time. The mean of 2 independent C-IMT determinations carried out 2 weeks apart was adopted for statistical analyses. Readings were taken at the far wall of the whole CC, Bif, and the first proximal $\mathrm{cm}$ of the ICA. The 2 independent C-IMT determinations were also used for the repeatability evaluation. The absolute differences (mean $\pm S D)$ between baseline replicate scans were $0.012 \pm 0.010,0.044 \pm 0.045,0.043 \pm 0.046,0.020 \pm 0.025$ and $0.085 \pm 0.109 \mathrm{~mm}$ for CC-IMT mean, Bif-IMT mean, ICA-IMT mean, IMT mean and IMT max, respectively. The same figures obtained at the last visit were $0.011 \pm 0.009 \mathrm{~mm}, 0.041 \pm 0.037 \mathrm{~mm}, 0.036 \pm 0.035$ $\mathrm{mm}, 0.015 \pm 0.013 \mathrm{~mm}, 0.080 \pm 0.087 \mathrm{~mm}$, respectively.

All baseline common carotid scans were measured again at the end of the study in order to assess whether a systematic change in readers' skill could have biased the estimate of IMT progression; no systematic differences were found $(0.765 \pm 0.142$ and $0.763 \pm 0.141 \mathrm{~mm} ; \mathrm{p}=0.2$ ).

\section{Laboratory tests}

As a panel of inflammation and coagulation markers, plasma levels of high-sensitivity Creactive protein (hs-CRP), tumour necrosis factor- $\alpha$ (TNF- $\alpha$ ), interleukin-6 (IL-6), interleukin-8 (IL-8), interleukin-18 (IL-18), soluble CD40 ligand (sCD40L), matrix metalloproteinase-9 (MMP-9), fibrinogen, free and total tissue factor pathway inhibitor (TFPI-free and TFPI-total) were measured. Soluble intercellular adhesion molecule-1 (sICAM-1), soluble vascular cell adhesion molecule-1 (sVCAM-1), soluble E-selectin (sEselectin) and von Willebrand factor (VWF) were measured as endothelial cell activation markers. All variables were measured by commercial kits (all intra- and inter-assay 
coefficients of variation: $<6 \%$ ). Since changes from baseline were maintained over the course of the study, the averages between the $12^{\text {th }}$ month and last visit were reported as on-treatment values.

To assess whether changes in carotid IMT correlated with the global variations of inflammation/coagulation status, all markers of inflammation and coagulation were combined in an inflammation/coagulation score, computed by dichotomizing the data around each median value (see below). Similarly, all markers of endothelial activation were combined in an endothelial activation score and lipids were combined in a lipid score. A global soluble markers score (including all markers of inflammation, coagulation and endothelial activation) was also devised. Finally, in order to investigate the effect of changes of all variables considered, including lipids, a total score was also computed.

\section{Statistical analysis}

Concerning the main end point of the study, the sample size of 85 patients should give an assessment with a power of $80 \%$ and an alpha error of 0.003 (accounting for 18 multiple comparisons with Bonferroni correction), a correlation coefficient ( $r$ ) of at least 0.4 between each soluble marker and carotid IMT. Alternatively, our sample size allowed a power of $80 \%$ to detect as significant, with an alpha error of 0.05 , a regression of IMT mean of at least $-0.012 \mathrm{~mm} / \mathrm{yr}$, assuming a standard deviation of 0.04 .

Continuous data are expressed as mean \pm SD and median (interquartile range), whereas categorical data are expressed as number or percentage. Variables were tested for normal distribution using the Kolmogorow-Smirnov test. Variables with a skewed distribution were log-transformed before analysis. Variations between on-treatment and baseline values were assessed by paired sample $t$-test.

Correlations among changes of plasma levels of lipids and soluble markers and of IMT values were analyzed by Pearson correlation. Partial correlation between soluble 
markers and selected carotid IMT variables were computed adjusting for variations in totaland HDL-cholesterol and triglycerides. Multiple regression analysis with stepwise selection was used to identify variables independently associated with IMT changes.

To achieve the above-mentioned combined scores (lipid-score, inflammation/coagulation score, endothelial activation score, soluble markers score, and total score), variables were expressed as delta-values (on-treatment minus baseline) and were transformed into dichotomous variables by assigning a value of 1 for changes above the median and 0 for changes equal or below (except for HDL-C, for which the opposite was done). Each score was then computed by averaging the appropriate dichotomized variables.

Thus, lower scores indicate a greater on-treatment improvement of the specific "status" considered and high values a poorer improvement or worsening.

The use of combined scores instead of single variables adds power to the statistical analyses and limits the inflation of type 1 error, which is otherwise a problem when single variables are analyzed because of the high number of statistical tests performed. In the score analyses, we could employ a less stringent threshold for significance of $p=0.01$. Statistical analyses were done using SAS V8.2 software (SAS Institute Inc., Cary, NC, USA). 


\section{Results}

Patients

Between June 2002 and December 2004, about 600 patients were screened and 85 who met all the inclusion/exclusion criteria received the treatment.

One patient who died after 18 months from enrolment for reasons not related to cardiovascular disease was included into the analyses because data from the $12^{\text {th }}$ month visit were available. No other serious adverse events were observed. 3 patients dropped out immediately after the baseline visit ( 1 by withdrawing informed consent and 2 because of a newly diagnosed cancer) and were excluded from the analyses. Baseline demographic characteristics and concomitant medications of the enrolled patients are shown in table 1 . No change in concomitant medications during follow-up was recorded. Compliance, defined as acceptable if at least $85 \%$ of study medication was consumed, was assessed every 12 months and averaged $90.1 \%$.

\section{Follow-up}

The study was finally approved on 04/06/2003 and had to be concluded by 01/01/2006. Since the period of patients' recruitment was longer than foreseen, only 28 patients (34\%) reached 24 months' follow-up, $31(37.8 \%)$ had a follow-up of at least 18 months, 11 $(13.4 \%)$ of at least 15 months and $12(14.6 \%)$ of at least 12 months (Figure 1$)$. The mean follow-up of the whole group was $20 \pm 3.7$ months. 
Baseline and on-treatment values of lipids and soluble markers

Table 2 shows the baseline and on-treatment values of lipids and soluble markers. As expected, atorvastatin induced a significant and optimal reduction in total- and LDLcholesterol and triglycerides and a moderate (4\%) increase of HDL-cholesterol.

Almost all on-treatment soluble markers decreased from baseline, except for hsCRP, IL-18, TFPI-free and sVCAM-1 which did not change significantly, and IL-6, TNF- $\alpha$ and SCD40L which were increased. After applying the Bonferroni correction SCD40L, fibrinogen, TFPI-total, sICAM-1, sE-selectin and VWF were significantly changed, whereas the significance of IL-8 was borderline.

\section{Correlation among changes of plasma variables}

Pearson correlation analyses between changes (on-treatment minus baseline) in each logtransformed plasma variable vs. all the others show that apart from the expected correlations between change in total-Cholesterol and LDL-C or triglycerides, only the correlations between changes in hs-CRP and changes in fibrinogen or IL- 6 and between sCD40L and MMP-9 reached the Bonferroni threshold value of $p(<0.0004)$ selected to account for 136 multiple comparisons. The positive correlation between IL-8 and MMP-9 $(r=0.38)$ reached $p<0.001$. The positive correlation between total-Cholesterol and TFPItotal, between fibrinogen and IL-6, between TNF- $\alpha$ and SCD40L, and between sE-selectin and TFPI-free (all $r \approx 0.30$ ) all reached $p<0.01$. All the other significant correlations observed (triglycerides vs LDL-C, $r=0.28$; IL- 6 vs HDL-C, $r=-0.23$; MMP-9 vs TNF- $\alpha, r=$ 0.25 ; IL-18 vs sICAM-1 or sVCAM-1, $r=0.28$ and 0.22 , respectively; sE-selectin vs triglycerides, fibrinogen and IL-8, $r=0.26,-0.22$ and 0.26 , respectively; and TFPI-total vs LDL-C, hs-CRP and sVCAM-1, all $r \approx 0.25$ ) reached $p$ values $<0.05$. 


\section{Changes in carotid IMT}

Table 3 shows the baseline and on-treatment values of carotid IMT as well as the yearly changes in log-transformed IMT for each ultrasonic variable considered. A fully significant regression was observed in 2 out of 4 ultrasonic variables (ICA-IMTmean, $p<0.002$ and IMT mean, $p<0.004)$ and borderline significant for Bif-IMTmean $(p=0.05)$. All analyses evaluating the relationship between changes in carotid atherosclerosis and changes in soluble markers were limited to the 2 variables with fully significantly regression.

Correlation between changes in ICA-IMT mean, IMT mean and plasma variables measured at baseline

In the Pearson correlation analysis, no correlation was observed between changes in logtransformed ultrasonic variables (ICA-IMT mean and IMT mean) and baseline log-transformed values of lipids or soluble markers. The unique exception was a negative correlation between changes in IMT mean and baseline vWF $(r=0.24 ; p=0.05)$, but the $p$ value was much higher than the Bonferroni threshold $(p=0.003$, calculated considering 18 multiple comparisons). The partial-correlation analysis, adjusted for age, gender and lipids and pharmacological treatments yielded similar results.

In the stepwise multiple regression analyses performed by using log-transformed carotid IMTs changes as dependent variable and all the other baseline log-transformed plasma variables (including lipids) as independent, only HDL-C inversely, but weakly, associated with $\mathrm{IMT}_{\operatorname{mean}}(\beta=-0.05239, \mathrm{SEM}=0.02238, \mathrm{p}=0.02)$. 
Correlation between changes in carotid IMTs and changes in plasma variables

No significant correlation was found between changes in lipids (triglycerides and total-, LDL- and HDL-Cholesterol) and changes in carotid IMTs. This was also confirmed after stratification in tertiles of LDL-C changes (Figure 2a and $2 b$ ); even if a weak trend seems to be present none of the ultrasonic endpoints tested reached statistical significance.

Table 2 shows the Pearson and Partial (adjusted for lipids) correlation coefficients between changes in log-transformed ICA-IMTmean, IMTmean and changes of logtransformed soluble markers. Positive and significant unadjusted correlations were observed only between ICA-IMT mean and both sE-Selectin and TFPI-total.

After adjustment for lipids (total-Cholesterol, HDL-Cholesterol and triglycerides) we still found significant correlations but none reached the $p<0.003$ value needed to account for Bonferroni correction with 18 comparisons.

\section{Correlations between IMT progression and variation scores}

Table 3 shows the correlation coefficients between changes in ICA-IMT mean, IMT mean and changes of soluble markers combined in 5 specific scores. Excluding those with the lipid score, which did not correlate at all, all the other correlations reached a $p$ value $<0.05$ and 5 even $<0.01$, the threshold value needed using the Bonferroni correction for 5 comparisons. No significant correlation was observed between the lipid score and any other score considered. 


\section{Discussion}

Carotid IMT regression has been observed in almost all clinical trials of high-dose atorvastatin (80 mg/daily).[4-6] Our data show that a moderate dose of atorvastatin (20 $\mathrm{mg} /$ daily) also produces significant IMT regression in patients with post-infarction stable CAD, in agreement with two previous studies using a low/moderate dose of atorvastatin in patients with stable CAD.[7, 8] Two further studies of patients with peripheral vascular disease[9] or of asymptomatic patients with vascular risk factors[10] treated with low/moderate doses of atorvastatin both showed an atorvastatin-induced regression of carotid IMT.

The MIAMI study evaluated the relationship between changes in a large panel of soluble markers representing inflammation/coagulation and endothelial activation pathways and simultaneous changes in carotid atherosclerosis. This provided a unique opportunity to determine whether the antiatherosclerotic effect of this statin is attributable to its lipid-lowering action only or whether other mechanisms are involved. Data here presented indicate that, even though the IMT changes did not correlate, or did so only poorly, with changes in any single soluble marker (or indeed with lipids), they did correlate with changes in combined scores of markers associated with atherogenesis.

In acute coronary syndrome, molecules directly involved in inflammatory/thrombotic processes play a prominent and easily assessable role. In contrast, in post-infarction stable clinical conditions this role is not so prominent. This may be why their effect is detectable only with groups of molecules acting in concert and not with single soluble markers.

The association of soluble markers with atherosclerosis progression depends on whether the disease is in an acute or chronic phase. The response to statins, and whether they are administered at high or moderate dose, may likewise depend on the phase of the disease. Large clinical trials have shown that high doses of statins, when administered in a 
very early phase of acute coronary syndrome, result in a lower number of cardiovascular events than with placebo[11] or moderate doses[12], an effect ascribed to the reduction of both LDL-C and hs-CRP.[13, 14] These trials suggest that lowering LDL-C may not in itself be effective in the extremely early phases of acute coronary syndrome, in which an enhanced inflammatory state and a high thrombogenic potential coexist, making all the more desirable the marked decrease in hs-CRP induced by a high dose of statin. On the other hand, in patients with vascular risk factors $[15,16]$ and in conditions of post-infarction clinical stability,[17] low/moderate doses of statins are highly effective in reducing clinical events as well as in reducing the "smouldering" inflammatory and thrombogenic activity measured in atherosclerotic plaques of stable subjects.[18] The data reported in the present study are well in line with these considerations. They confirm, in fact, that in the phase of post-infarction clinical stability, the rate of IMT-progression/regression, even if not attributable to modulation of single markers involved in atherothrombosis, is robustly correlated with variations of subsets of molecules involved in inflammation/coagulation or endothelial activation. Further, our data are consistent with the concept that the action of statins in plaque stabilization involves different sets of soluble molecules depending on the phase of the disease (acute or chronic) in which the drug is used.

On-treatment concentrations of fibrinogen, IL-8, MMP-9, sICAM-1, sE-selectin and vWF were significantly lower than before treatment. Since all these molecules are involved in atherogenesis,[19-23] and since their changes were unrelated to changes in lipids, these findings suggest a pleiotropic effect of atorvastatin. By contrast, IL-6, SCD40L and TNF- $\alpha$ increased in response to treatment, (even if $p$ values of changes in IL-6 and TNF- $\alpha$ did not reach the statistical threshold of Bonferroni correction for multiple comparison) but remaining within the normal range $(0.4-9.5 \mathrm{pg} / \mathrm{ml}, 0.03-3.98 \mathrm{ng} / \mathrm{ml}$ and $0.0-4.2 \mathrm{pg} / \mathrm{ml}$ respectively). As far as $\mathrm{SCD} 40 \mathrm{~L}$ is concerned, since only much higher values predict ischemic events[24], the observed changes are probably not of clinical relevance. 
Another apparently harmful effect observed here and in other studies with different statins[25-28] is the reduction of TFPI-total, which normally circulates complexed with LDLC.[29] However, since the anticoagulant potency of TFPI is actually restricted to TFPIfree,[30] which was unchanged on treatment, it is unlikely that this reduction influenced the available anticoagulant activity.

IL-18, sVCAM-1 and hs-CRP underwent no significant change during treatment. Almost all the studies published so far, whether carried out in patients with vascular risk factors[31-37] or in patients with acute[13, 14, 38] or stable CAD[39-41] reported a significant reduction of hs-CRP. To the best of our knowledge, only 1 study has shown a lack of effect of atorvastatin on hs-CRP[31], when baseline levels of this molecule were in the lowest quartile. This suggests that the statin has an effect only when patients have a heightened inflammatory state.

If the relationship between baseline hs-CRP values and hs-CRP response to treatment is analyzed for all the studies published so far, $[6,8,31,38,39,41-45]$ a very strong linear correlation can be detected (Figure 3). In our study, hs-CRP levels fell by about $16 \%$, a value in agreement with the general trend reported in the figure. From this figure it is also apparent that there is no relationship to the dose of atorvastatin, a conclusion confirmed by at least 2 studies properly designed to address this topic,[31, 46] but not with another $4 .[6,34,38,47]$ Changes in IL-6 and in hs-CRP levels showed an opposite trend. Inasmuch as IL-6 is a main stimulus for CRP synthesis [48-50], this observation may seem counterintuitive. Yet, changes in either direction of both parameters observed in the present study did not reach the statistical threshold value of Bonferroni correction for multiple comparison and thus could be the result of chance. 


\section{Limitation of the study}

The main limitation of the present study is the lack of a placebo group, for ethical reasons: post-infarction patients cannot be left untreated. The present study could not therefore prove a causal effect of atorvastatin treatment and could not exclude that the observed changes in biomarkers and IMT were due to temporal changes or to other reasons. However, since it is well known that in absence of pharmacological treatments carotid IMT progresses, and since the concomitant treatments were unmodified at the entrance to or during the study, IMT regression is unlikely to have been either spontaneous or result from the other treatments. A spontaneous change in blood levels of soluble markers is also improbable since the patients were in a stable phase of the disease, at least 2 months after the acute coronary event.

\section{Conclusion}

In patients in a post-infarction stable condition, treated with moderate doses of atorvastatin, carotid IMT regression correlated with changes of inflammation, thrombosis and endothelial activation profiles. 


\section{References}

[1] LaRosa JC, He J, Vupputuri S. Effect of statins on risk of coronary disease: a metaanalysis of randomized controlled trials. Jama 1999;282(24):2340-6.

[2] Schonbeck U, Libby P. Inflammation, immunity, and HMG-CoA reductase inhibitors: statins as antiinflammatory agents? Circulation 2004;109(21 Suppl 1):II18-26.

[3] Porta B, Baldassarre D, Camera M, Amato M, Arquati M, Brusoni B, Fiorentini C, Montorsi P, Romano S, Tremoli E, Cortellaro M. E-selectin and TFPI are associated with carotid intima-media thickness in stable IHD patients: The baseline findings of the MIAMI study. Nutr Metab Cardiovasc Dis 2007.

[4] Smilde TJ, van Wissen S, Wollersheim H, Trip MD, Kastelein JJ, Stalenhoef AF. Effect of aggressive versus conventional lipid lowering on atherosclerosis progression in familial hypercholesterolaemia (ASAP): a prospective, randomised, double-blind trial. Lancet 2001;357(9256):577-81.

[5] Taylor AJ, Kent SM, Flaherty PJ, Coyle LC, Markwood TT, Vernalis MN. ARBITER: Arterial Biology for the Investigation of the Treatment Effects of Reducing Cholesterol: a randomized trial comparing the effects of atorvastatin and pravastatin on carotid intima medial thickness. Circulation 2002;106(16):2055-60.

[6] Yu CM, Zhang Q, Lam L, Lin H, Kong SL, Chan W, Fung JW, Cheng KK, Chan IH, Lee SW, Sanderson JE, Lam CW. Comparison of intensive and low-dose atorvastatin therapy in the reduction of carotid intimal-medial thickness in patients with coronary heart disease. Heart 2007;93(8):933-9.

[7] Shukla A, Sharma MK, Jain A, Goel PK. Prevention of atherosclerosis progression using atorvastatin in normolipidemic coronary artery disease patients--a controlled randomized trial. Indian Heart J 2005;57(6):675-80. 
[8] Ozaki K, Kubo T, Imaki R, Shinagawa H, Fukaya H, Ohtaki K, Ozaki S, Izumi T, Aizawa $\mathrm{Y}$. The anti-atherosclerotic effects of lipid lowering with atorvastatin in patients with hypercholesterolemia. J Atheroscler Thromb 2006;13(4):216-9.

[9] Youssef F, Seifalian AM, Jagroop IA, Myint F, Baker D, Mikhailidis DP, Hamilton G. The early effect of lipid-lowering treatment on carotid and femoral intima media thickness (IMT). Eur J Vasc Endovasc Surg 2002;23(4):358-64.

[10] Sugiyama M, Ohashi M, Takase H, Sato K, Ueda R, Dohi Y. Effects of atorvastatin on inflammation and oxidative stress. Heart Vessels 2005;20(4):133-6.

[11] Schwartz GG, Olsson AG, Ezekowitz MD, Ganz P, Oliver MF, Waters D, Zeiher A, Chaitman BR, Leslie S, Stern T. Effects of atorvastatin on early recurrent ischemic events in acute coronary syndromes: the MIRACL study: a randomized controlled trial. Jama 2001;285(13):1711-8.

[12] Cannon CP, Braunwald E, McCabe CH, Rader DJ, Rouleau JL, Belder R, Joyal SV, Hill KA, Pfeffer MA, Skene AM. Intensive versus moderate lipid lowering with statins after acute coronary syndromes. N Engl J Med 2004;350(15):1495-504.

[13] Kinlay S, Schwartz GG, Olsson AG, Rifai N, Leslie SJ, Sasiela WJ, Szarek M, Libby P, Ganz P. High-dose atorvastatin enhances the decline in inflammatory markers in patients with acute coronary syndromes in the MIRACL study. Circulation 2003;108(13):1560-6.

[14] Ridker PM, Cannon CP, Morrow D, Rifai N, Rose LM, McCabe CH, Pfeffer MA, Braunwald E. C-reactive protein levels and outcomes after statin therapy. N Engl J Med 2005;352(1):20-8.

[15] Sever PS, Dahlof B, Poulter NR, Wedel H, Beevers G, Caulfield M, Collins R, Kjeldsen SE, Kristinsson A, Mclnnes GT, Mehlsen J, Nieminen M, O'Brien E, Ostergren J. Prevention of coronary and stroke events with atorvastatin in hypertensive patients who have average or lower-than-average cholesterol 
concentrations, in the Anglo-Scandinavian Cardiac Outcomes Trial--Lipid Lowering Arm (ASCOT-LLA): a multicentre randomised controlled trial. Lancet 2003;361(9364):1149-58.

[16] Colhoun HM, Betteridge DJ, Durrington PN, Hitman GA, Neil HA, Livingstone SJ, Thomason MJ, Mackness MI, Charlton-Menys V, Fuller JH. Primary prevention of cardiovascular disease with atorvastatin in type 2 diabetes in the Collaborative Atorvastatin Diabetes Study (CARDS): multicentre randomised placebo-controlled trial. Lancet 2004;364(9435):685-96.

[17] MRC/BHF Heart Protection Study of cholesterol lowering with simvastatin in 20,536 high-risk individuals: a randomised placebo-controlled trial. Lancet 2002;360(9326):7-22.

[18] Cortellaro M, Cofrancesco E, Arbustini E, Rossi F, Negri A, Tremoli E, Gabrielli L, Camera M. Atorvastatin and thrombogenicity of the carotid atherosclerotic plaque: the ATROCAP study. Thromb Haemost 2002;88(1):41-7.

[19] Ernst E, Resch KL. Fibrinogen as a cardiovascular risk factor: a meta-analysis and review of the literature. Ann Intern Med 1993;118(12):956-63.

[20] Gerszten RE, Garcia-Zepeda EA, Lim YC, Yoshida M, Ding HA, Gimbrone MA, Jr., Luster AD, Luscinskas FW, Rosenzweig A. MCP-1 and IL-8 trigger firm adhesion of monocytes to vascular endothelium under flow conditions. Nature 1999;398(6729):718-23.

[21] Galis ZS, Khatri JJ. Matrix metalloproteinases in vascular remodeling and atherogenesis: the good, the bad, and the ugly. Circ Res 2002;90(3):251-62.

[22] Blankenberg S, Barbaux S, Tiret L. Adhesion molecules and atherosclerosis. Atherosclerosis 2003;170(2):191-203.

[23] Blann AD. Plasma von Willebrand factor, thrombosis, and the endothelium: the first 30 years. Thromb Haemost 2006;95(1):49-55. 
[24] Kinlay S, Schwartz GG, Olsson AG, Rifai N, Sasiela WJ, Szarek M, Ganz P, Libby P. Effect of atorvastatin on risk of recurrent cardiovascular events after an acute coronary syndrome associated with high soluble CD40 ligand in the Myocardial Ischemia Reduction with Aggressive Cholesterol Lowering (MIRACL) Study. Circulation 2004;110(4):386-91.

[25] Hansen JB, Huseby KR, Huseby NE, Sandset PM, Hanssen TA, Nordoy A. Effect of cholesterol lowering on intravascular pools of TFPI and its anticoagulant potential in type II hyperlipoproteinemia. Arterioscler Thromb Vasc Biol 1995;15(7):879-85.

[26] Nordoy A, Bonaa KH, Sandset PM, Hansen JB, Nilsen H. Effect of omega-3 fatty acids and simvastatin on hemostatic risk factors and postprandial hyperlipemia in patients with combined hyperlipemia. Arterioscler Thromb Vasc Biol 2000;20(1):259-65.

[27] Morishita E, Asakura H, Saito M, Yamazaki M, Ontachi Y, Mizutani T, Kato M, Matsuda T, Nakao S. Elevated plasma levels of free-form of TFPI antigen in hypercholesterolemic patients. Atherosclerosis 2001;154(1):203-12.

[28] Sebestjen M, Keber I, Zegura B, Simcic S, Bozic M, Fressart MM, Stegnar M. Statin and fibrate treatment of combined hyperlipidemia: the effects on some novel risk factors. Thromb Haemost 2004;92(5):1129-35.

[29] Hansen JB, Huseby NE, Sandset PM, Svensson B, Lyngmo V, Nordoy A. Tissuefactor pathway inhibitor and lipoproteins. Evidence for association with and regulation by LDL in human plasma. Arterioscler Thromb 1994;14(2):223-9.

[30] Lindahl AK, Jacobsen PB, Sandset PM, Abildgaard U. Tissue factor pathway inhibitor with high anticoagulant activity is increased in post-heparin plasma and in plasma from cancer patients. Blood Coagul Fibrinolysis 1991;2(6):713-21.

[31] Riesen WF, Engler H, Risch M, Korte W, Noseda G. Short-term effects of atorvastatin on C-reactive protein. Eur Heart J 2002;23(10):794-9. 
[32] Chan DC, Watts GF, Barrett PH, Beilin LJ, Mori TA. Effect of atorvastatin and fish oil on plasma high-sensitivity C-reactive protein concentrations in individuals with visceral obesity. Clin Chem 2002;48(6 Pt 1):877-83.

[33] Costa A, Casamitjana R, Casals E, Alvarez L, Morales J, Masramon X, Hernandez G, Gomis R, Conget I. Effects of atorvastatin on glucose homeostasis, postprandial triglyceride response and C-reactive protein in subjects with impaired fasting glucose. Diabet Med 2003;20(9):743-5.

[34] van de Ree MA, Huisman MV, Princen HM, Meinders AE, Kluft C. Strong decrease of high sensitivity C-reactive protein with high-dose atorvastatin in patients with type 2 diabetes mellitus. Atherosclerosis 2003;166(1):129-35.

[35] Yamada S, Yanagawa T, Sasamoto K, Araki A, Miyao M, Yamanouchi T. Atorvastatin lowers plasma low-density lipoprotein cholesterol and C-reactive protein in Japanese type 2 diabetic patients. Metabolism 2006;55(1):67-71.

[36] Ballantyne CM, Houri J, Notarbartolo A, Melani L, Lipka LJ, Suresh R, Sun S, LeBeaut AP, Sager PT, Veltri EP. Effect of ezetimibe coadministered with atorvastatin in 628 patients with primary hypercholesterolemia: a prospective, randomized, double-blind trial. Circulation 2003;107(19):2409-15.

[37] Kent SM, Flaherty PJ, Coyle LC, Markwood TT, Taylor AJ. Effect of atorvastatin and pravastatin on serum C-reactive protein. Am Heart J 2003;145(2):e8.

[38] Ordulu E, Erdogan O. Early effects of low versus high dose atorvastatin treatment on coagulation and inflammation parameters in patients with acute coronary syndromes. Int J Cardiol 2007.

[39] Kinlay S, Timms T, Clark M, Karam C, Bilodeau T, Ridker PM, Rifai N, Carlson W, Lloyd-Jones DM, Johnstone M, Rubenstein J, Alexander S, Orav J, Stone PH. Comparison of effect of intensive lipid lowering with atorvastatin to less intensive 
lowering with lovastatin on C-reactive protein in patients with stable angina pectoris and inducible myocardial ischemia. Am J Cardiol 2002;89(10):1205-7.

[40] Nissen SE, Tuzcu EM, Schoenhagen P, Brown BG, Ganz P, Vogel RA, Crowe T, Howard G, Cooper CJ, Brodie B, Grines CL, DeMaria AN. Effect of intensive compared with moderate lipid-lowering therapy on progression of coronary atherosclerosis: a randomized controlled trial. Jama 2004;291(9):1071-80.

[41] Alber HF, Frick M, Sussenbacher A, Dorler J, Dichtl W, Stocker EM, Pachinger O, Weidinger F. Effect of atorvastatin on peripheral endothelial function and systemic inflammatory markers in patients with stable coronary artery disease. Wien Med Wochenschr 2007;157(3-4):73-8.

[42] Jialal I, Stein D, Balis D, Grundy SM, Adams-Huet B, Devaraj S. Effect of hydroxymethyl glutaryl coenzyme a reductase inhibitor therapy on high sensitive Creactive protein levels. Circulation 2001;103(15):1933-5.

[43] van Wissen S, Trip MD, Smilde TJ, de Graaf J, Stalenhoef AF, Kastelein JJ. Differential hs-CRP reduction in patients with familial hypercholesterolemia treated with aggressive or conventional statin therapy. Atherosclerosis 2002;165(2):361-6.

[44] Ascer E, Bertolami MC, Venturinelli ML, Buccheri V, Souza J, Nicolau JC, Ramires $\mathrm{JA}$, Serrano CV, Jr. Atorvastatin reduces proinflammatory markers in hypercholesterolemic patients. Atherosclerosis 2004;177(1):161-6.

[45] Nissen SE, Tuzcu EM, Schoenhagen P, Crowe T, Sasiela WJ, Tsai J, Orazem J, Magorien RD, O'Shaughnessy C, Ganz P. Statin therapy, LDL cholesterol, Creactive protein, and coronary artery disease. N Engl J Med 2005;352(1):29-38.

[46] Blanco-Colio LM, Martin-Ventura JL, de Teresa E, Farsang C, Gaw A, Gensini G, Leiter LA, Langer A, Martineau P, Hernandez G, Egido J. Increased soluble Fas plasma levels in subjects at high cardiovascular risk: Atorvastatin on Inflammatory 
Markers (AIM) study, a substudy of ACTFAST. Arterioscler Thromb Vasc Biol 2007;27(1):168-74.

[47] Kinlay S. Low-density lipoprotein-dependent and -independent effects of cholesterol-lowering therapies on C-reactive protein: a meta-analysis. J Am Coll Cardiol 2007;49(20):2003-9.

[48] Cohen MC, Cohen S. Cytokine function: a study in biologic diversity. Am J Clin Pathol 1996;105(5):589-98.

[49] Papanicolaou DA, Wilder RL, Manolagas SC, Chrousos GP. The pathophysiologic roles of interleukin-6 in human disease. Ann Intern Med 1998;128(2):127-37.

[50] Gabay C, Kushner I. Acute-phase proteins and other systemic responses to inflammation. N Engl J Med 1999;340(6):448-54. 


\section{Appendices}

\section{The MIAMI Study Group}

\section{Coordinating Center}

Department of Clinical Sciences, L Sacco Hospital, Milan University, Milan: M. Cortellaro (Principal Investigator), B. Porta, M. Arquati.

\section{Cardiologic Units}

Centro Cardiologico Monzino IRCCS, Milan: P. Montorsi (Head), M. Alimento, P. Ravagnani

Fatebenefratelli Hospital, Milan: B. Brusoni (Head), M. Bonaita

Ospedale Maggiore IRCCS, Milan: S. Romano (Head), L. Mircoli

San Paolo Hospital, Milan University, Milan: C. Fiorentini (Head), C. Corti

\section{Participating laboratories}

Centro Cardiologico Monzino IRCCS, Milan University, Milan: E. Tremoli (Head), D.

Baldassarre, M. Camera, M. Amato, C. Biancardi, A. Ravani, P. Massironi

\section{Unit of biostatistics}

F. Veglia (Principal Biostatistician) 
TABLE 1. Patient's clinical characteristics at baseline

\begin{tabular}{lc}
\hline Characteristic & Value \\
\hline Age (yrs, mean \pm SD) & $57.5 \pm 8.1$ \\
Gender (male/female) & $72 / 13$ \\
SBP (mmHg, mean $\pm \mathrm{SD})$ & $127.3 \pm 11.3$ \\
DBP (mmHg, mean $\pm \mathrm{SD})$ & $78.3 \pm 7.0$ \\
BMI (Kg/m², mean $\pm \mathrm{SD})$ & $26.2 \pm 3.2$ \\
Current smoker (\%) & 12.9 \\
Hypertension (\%) & 44.7 \\
Diabetes (\%) & $0 *$ \\
Parental history of CVD (\%) & 53.7 \\
History of angina (\%) & 7.10 \\
Previous coronary revascularization & \\
PTCA (\%) & 75.3 \\
CABG (\%) & 8.2 \\
Current medication and previous statin use & \\
ACE inhibitors (low dosage) (\%) & 22.4 \\
$\beta$-blockers (\%) & 63.7 \\
Aspirin (\%) & 97.6 \\
Diuretic drugs (\%) & 11.8 \\
Antiarrhythmic drugs (\%) & \\
Previous statin use (\%) & \\
\hline$* x .0$
\end{tabular}

\footnotetext{
${ }^{*}$ exclusion criterion, CVD, cardiovascular disease; BMI, body mass index; PTCA, percutaneous transcatheter coronary angioplasty; $C A B G$, coronary artery bypass graft.
} 
Table 2: Baseline and on-treatment values of lipids and soluble markers

\begin{tabular}{|c|c|c|c|c|}
\hline Variables & $\begin{array}{c}\text { Baseline } \\
(n=85)\end{array}$ & $\begin{array}{c}\text { On-treatment }{ }^{\star} \\
(\mathrm{n}=82)\end{array}$ & Change & $\mathbf{P}$ \\
\hline \multicolumn{5}{|l|}{ Lipids } \\
\hline Total-C (mg/dl) & $223(207 ; 250)$ & $149(134.5 ; 182)$ & $-69(-78 ;-60)$ & 0.0001 \\
\hline HDL-C (mg/dl) & $43.5(40 ; 53)$ & $46.8(40 ; 53.5)$ & $2(0 ; 4)$ & 0.03 \\
\hline LDL-C (mg/dl) & $150(129 ; 171)$ & $82(71 ; 104)$ & $-63(-71 ;-56)$ & 0.0001 \\
\hline Triglycerides (mg/dl) & $150(96 ; 182)$ & $114(83 ; 156)$ & $-25(-38 ;-11)$ & 0.0001 \\
\hline \multicolumn{5}{|c|}{ Inflammation/coagulation markers } \\
\hline hs-CRP $(\mu \mathrm{g} / \mathrm{ml})$ & $1.04(0.52 ; 2.1)$ & $0.87(0.58 ; 1.75)$ & $-0.35(-0.7 ; 0.0)$ & 0.08 \\
\hline IL-6 (pg/ml) & $1.6(1.1 ; 2.7)$ & $1.9(1.4 ; 3.2)$ & $0.35(-0.12 ; 0.82)$ & 0.02 \\
\hline $\mathrm{IL}-8(\mathrm{pg} / \mathrm{ml})$ & $7.5(3.5 ; 12.2)$ & $4.9(1.6 ; 8.6)$ & $-2.6(-4.7 ;-0.6)$ & 0.004 \\
\hline IL-18 (pg/ml) & $174(141 ; 215)$ & $163(137 ; 200)$ & $-5.8(-16 ; 4.4)$ & 0.32 \\
\hline TNF- $\alpha(p g / m l)$ & $1.0(0.7 ; 1.6)$ & $1.3(1.0 ; 1.6)$ & $-0.2(-0.7 ; 0.2)$ & 0.04 \\
\hline sCD40L (ng/ml) & $2.3(1.2 ; 3.4)$ & $3.1(2.1 ; 4.2)$ & $0.52(0.01 ; 1.02)$ & 0.002 \\
\hline MMP-9 (ng/ml) & $392(273 ; 542)$ & $352(260 ; 463)$ & $-94(-158 ;-30)$ & 0.04 \\
\hline Fibrinogen (mg/dl) & $363(333 ; 410)$ & $327(303 ; 381)$ & $-27(-38 ;-16)$ & 0.0001 \\
\hline TFPI-total (ng/ml) & $70(61 ; 80)$ & $57(49 ; 67)$ & $-12(-15 ;-9)$ & 0.0001 \\
\hline TFPl-free (ng/ml) & $9.6(7.9 ; 11.7)$ & $9.1(7.8 ; 11.1)$ & $-0.9(-2.0 ; 0.2)$ & 0.09 \\
\hline \multicolumn{5}{|c|}{ Markers of endothelial activation } \\
\hline slCAM-1 (ng/ml) & $241(211 ; 273)$ & $219(191 ; 254)$ & $-20(-30 ;-11)$ & 0.0001 \\
\hline sVCAM-1 (ng/ml) & $552(476 ; 661)$ & $542(474 ; 669)$ & $2(-18 ; 23)$ & 0.82 \\
\hline sE-selectin (ng/ml) & $32(22 ; 42)$ & $22(15 ; 28)$ & $-11(-13 ;-9)$ & 0.0001 \\
\hline VWF (IU/ml) & $1.2(1.0 ; 1.5)$ & $0.9(0.7 ; 1.0)$ & $-0.4(-0.4 ;-0.3)$ & 0.0001 \\
\hline
\end{tabular}

${ }^{*}$ Average between the 12-month and the last visits. Values are median and interquartile range except for "change " which are mean and 95\% C.I. (log-transformed). Statistical significance has been evaluated with log-transformed data. In bold are $p<0.004$ (threshold for Bonferroni correction with 18 multiple comparisons).

$\mathrm{SBP}=$ Systolic blood pressure, $\mathrm{DBP}=$ Diastolic blood pressure, $\mathrm{BMI}=$ body mass index . 
Table 3: Baseline and on-treatment values of carotid IMT

\begin{tabular}{lcccc}
\hline & Baseline & 12 month visit & Last visit & Yearly change in thickness P value vs zero \\
\hline CC-IMT mean & $0.69(0.65-0.75)$ & $0.69(0.64-0.77)$ & $0.69(0.65-0.74)$ & $-0.005(-0.011,0.001)$ \\
Bif-IMT mean & $1.04(0.87-1.33)$ & $1.01(0.86-1.27)$ & $0.97(0.84-1.29)$ & $-0.017(-0.035,0.000)$ \\
ICA-IMT mean & $0.83(0.68-1.15)$ & $0.77(0.66-1.08)$ & $0.78(0.67-1.06)$ & $-0.028(-0.045,-0.011)$ \\
IMT $_{\text {mean }}$ & $0.88(0.75-1.01)$ & $0.86(0.73-1.01)$ & $0.82(0.74-0.95)$ & $-0.013(-0.022,-0.004)$ \\
\hline
\end{tabular}

Values are median and interquartile range except for "Yearly change in thickness" which are mean and 95\% C.I. (log-transformed).

$\mathrm{IMT}=$ intima-media thickness, $\mathrm{CC}=$ common carotid, Bif=Bifurcation, ICA=internal carotid artery 
Table 4. Pearson and Partial (adjusted for changes in total-C, HDL-Cholesterol, triglycerides and pharmacological treatments) correlation coefficients and $p$ values (in lowercase) between changes in log-transformed ICA-IMT mean, IMT $_{\text {mean }}$ and changes of soluble markers (log-transformed).

\begin{tabular}{|c|c|c|c|c|}
\hline & \multicolumn{2}{|c|}{ ICA-IMT mean } & \multicolumn{2}{|c|}{$\mathrm{IMT}_{\text {mean }}$} \\
\hline & & Adjusted & & Adjusted \\
\hline & $\mathrm{R}$ & $\mathrm{R}$ & $\mathrm{R}$ & $\mathrm{R}$ \\
\hline TNF- $\alpha$ & 0,06 & $-0,04$ & $0,21_{0,08}$ & 0,02 \\
\hline sE-Selectin & $0,230,046$ & $0,30_{0,02}$ & 0,06 & 0,14 \\
\hline MMP-9 & 0,10 & 0,12 & $0,230,052$ & $0,250,057$ \\
\hline IL-8 & 0,14 & 0,18 & $0,220,06$ & $0,320,01$ \\
\hline TFPI-total & $0,310,007$ & $0,250,060$ & 0,14 & 0,10 \\
\hline vWF & 0,17 & $0,26_{0,050}$ & $0,21_{0,07}$ & $0,27_{0,04}$ \\
\hline
\end{tabular}

\footnotetext{
All plasma markers shown in Table 1 have been analyzed, but only those showing at least one significant correlation with at least one of IMT variables $(p<0.09)$ are reported in the table. Only correlations with a $p$ value $<0.003$ have to be considered as significant in order to taking into account for Bonferroni correction for multiple comparisons. Correlation have been performed after log-transformation of both ultrasonic variables and soluble markers.
} 


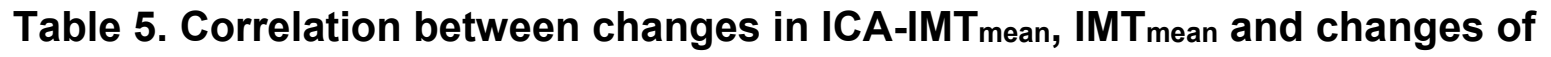
soluble markers combined in $\mathbf{5}$ specific scores

\section{Changes}

\section{ICA-IMT mean $\quad$ IMT}

\begin{tabular}{|c|c|c|}
\hline With lipid score & 0.12 & 0.10 \\
\hline Triglycerides, LDL- and HDL-cholesterol & $P=0.3$ & $P=0.4$ \\
\hline \multicolumn{3}{|l|}{ With inflammation/coagulation score } \\
\hline $\begin{array}{l}\text { (includes changes in: hs-CRP, IL-6, IL-8, IL-18, TNF-a, sCD40L, } \\
\text { MMP-9, fibrinogen, TFPI-total, TFPl-free) }\end{array}$ & $\begin{array}{c}0.25 \\
P=0.035\end{array}$ & $\begin{array}{c}0.29 \\
P=0.013\end{array}$ \\
\hline With endothelial activation score & 0.40 & 0.24 \\
\hline (includes changes in: sICAM-1, sVCAM-1, sE-selectin, vWF) & $P=0.0007$ & $P=0.04$ \\
\hline With soluble markers score & 0.35 & 0.32 \\
\hline (includes all variables used in the two previous scores) & $P=0.003$ & $P=0.007$ \\
\hline With total score & 0.38 & 0.35 \\
\hline (includes changes of all soluble markers considered and lipids) & $P=0.001$ & $P=0.003$ \\
\hline
\end{tabular}

In each score variables expressed as delta-values (on-treatment minus baseline) were transformed into dichotomous variables by assigning a value of 1 for changes above the median, and 0 for changes equal or below (except for HDL-C for which the opposite was done). Each score was then computed by averaging the appropriate dichotomized variables. Lower values indicates a higher improvement during treatment of the specific "status" considered (for example a higher improvement of the inflammation/coagulation status), and high values a poorer improvement. 


\section{Figure legends}

Figure 1. Individual follow-up of patients treated with atorvastatin.

Figure 2. Changes in log-transformed ICA-IMT mean (panel a) and IMTmean (panel b) by tertiles of LDL-C reduction. IMT = intima-media thickness, ICA=internal carotid artery.

Figure 3. Relationship between baseline hs-CRP values and the hs-CRP response to treatment in all the studies published so far. Numbers within markers are references. hs-CRP= high sensitive C-reactive protein 


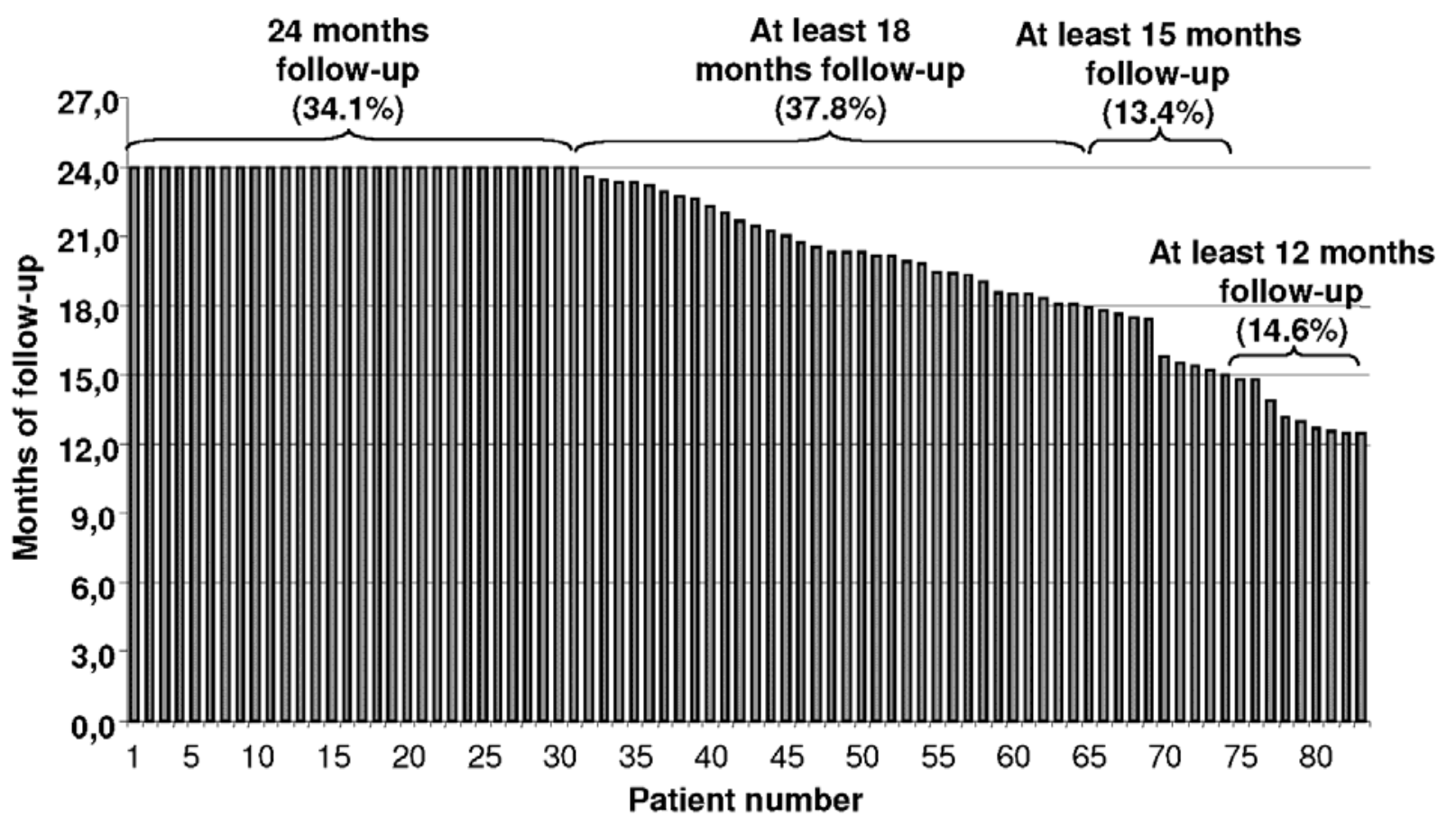

Figure 1 

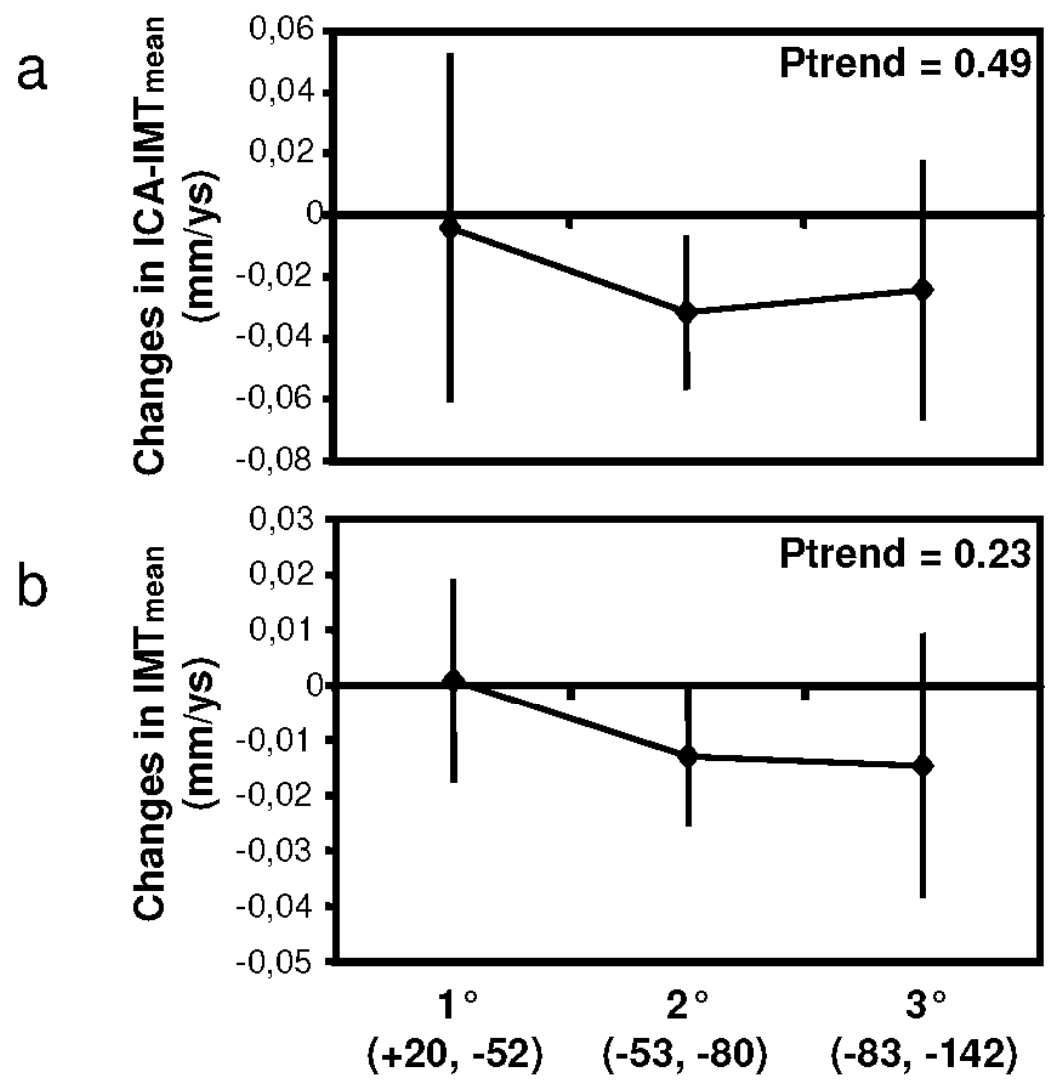

Tertiles of $L D L-C$ reduction (range $\mathrm{mg} / \mathrm{dL}$ )

Figure 2 


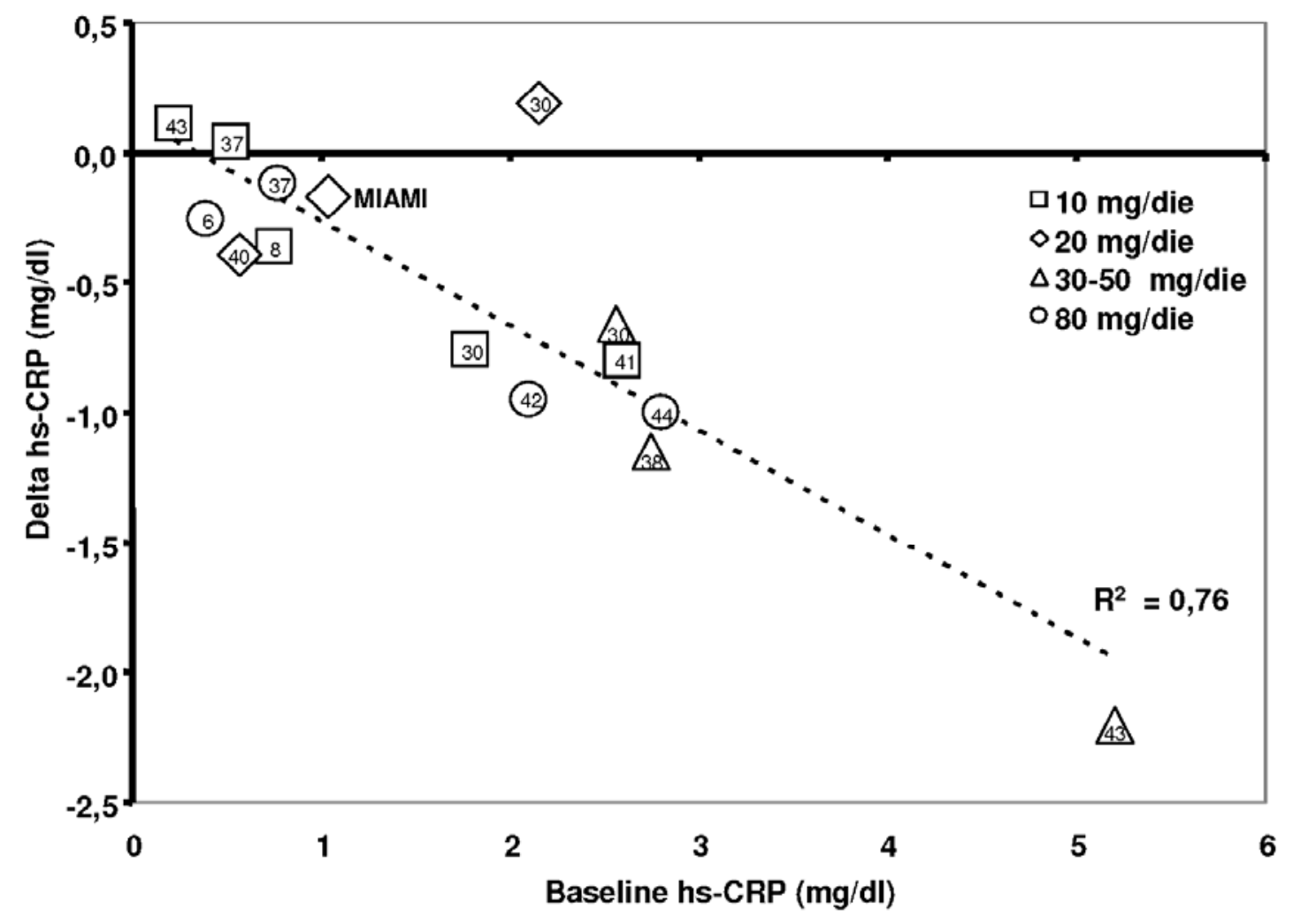

Figure 3 